\title{
Point-of care lung ultrasound in the NICU: uses and limitations of a new tool
}

\author{
Francesco Raimondi ${ }^{1 *}$, Fiorella Migliaro ${ }^{1}$, Angela Sodano ${ }^{1}$, Claudio Veropalumbo ${ }^{1}$, Angela Carla Borrelli ${ }^{1}$, \\ Silvia Lama', Gianfranco Vallone², Letizia Capasso ${ }^{1}$ \\ From XX National Congress of the Italian Society of Neonatology \\ Rome, Italy. 9-11 October 2014
}

Pulmonary imaging in the neonatal intensive care unit (NICU) relies traditionally on the conventional chest radiogram. Translating evidences from adult emergency medicine, pediatricians and neonatologists have recently started to apply lung ultrasonography to the critical infant and child with respiratory problems [1].

Because of the high impedance of a normally aerated lung, an ultrasound scan does not render an anatomical image of the organ. However, ultrasounds clearly define the pleural surface with the normal sliding movement. Pleural effusions and lung consolidations can also be reliably diagnosed with ultrasonography. However, ultrasounds penetrating the lung will also generate artifacts (i.e. structures not naturally present in the living that appear as authentic images). These imagery anomalies come from the machine acquisition of the ultrasound beam path through means with markedly different acoustic impedance in close proximity. The horizontal reverberations of the pleural line (aka the A lines - see Figure $1 \mathrm{~A}$ ) and the vertical hyperecoic image departing from the pleura (aka the B lines- see Figure 1B) are commonly seen artifacts.

Real and artefactual images have been combined in disease specific ultrasound profiles. Using these profiles, adult emergency physicians have shown that lung ultrasound outperforms conventional radiology in relevant diagnoses such as pleural effusion, pneumonia or pneumothorax.

Pediatricians have started to use lung ultrasound with success to their patients affected by pneumonia but also by bronchiolitis [2]. In the NICU, lung ultrasound has
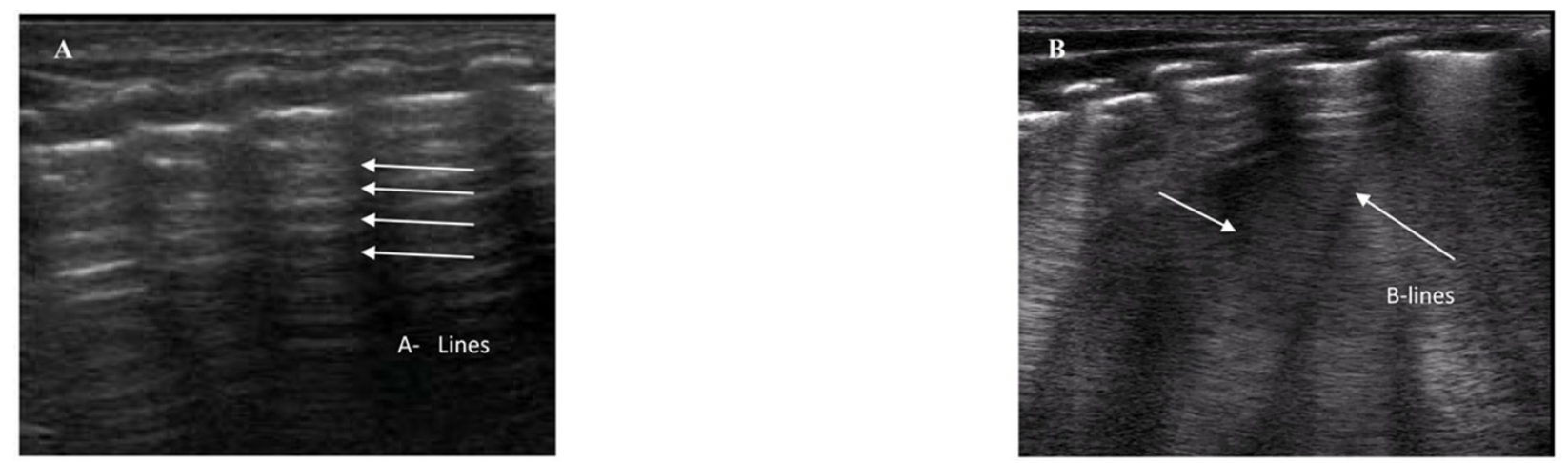

Figure 1 1A: reverberations of the pleural image (aka A-lines) in the normally aerated lung. 1B: the prevalence of vertical B-lines (in between arrows) has been linked to the interstitial syndrome in the adult and to a progressive aeration of the neonatal lung after birth.

'Division of Neonatology, Section of Pediatrics, Department of Medical

Translational Sciences, Università "Federico II", Naples, Italy

Full list of author information is available at the end of the article 
found its specific applications, not without controversies [3]. Transient Tachypnea of the Newborn and Respiratory Distress Syndrome have been described with ultrasound profiles that are both highly sensitive and specific [4]. A relevant limitation of chest ultrasound is that surfactant administration gives a persistent white lung image rendering any follow-up essentially unfeasible. Ultrasounds can, however, accurately describe the fluid to air transition after birth and identify those neonates who will fail to adapt to extrauterine life needing respiratory support [5]. In a series of preterm neonates with moderate respiratory distress, recent work by our group shows that chest ultrasound is significantly more accurate than conventional radiograph in predicting the failure of non invasive ventilation [6].

Lung ultrasound is a very promising clinical tool in the NICU whose potential applications are well worth future multicenter trials.

\section{Authors' details}

'Division of Neonatology, Section of Pediatrics, Department of Medical Translational Sciences, Università "Federico II", Naples, Italy. ${ }^{2}$ Section of Radiology, Department of Advanced Biomedical Science, Università "Federico II", Naples, Italy.

Published: 9 October 2014

\section{References}

1. Raimondi F, Cattarossi L, Copetti R: International Perspectives: Point-ofCare Chest Ultrasound in the Neonatal Intensive Care Unit: An Italian Perspective. NeoReviews 2014, 15:e2-e6.

2. Caiulo VA, Gargani L, Caiulo S, Fisicaro A, Moramarco F, Latini G, Picano E: Lung ultrasound in bronchiolitis: comparison with chest X-ray. Eur J Pediatr 2011, 170(11):1427-33.

3. Raimondi F, Cattarossi L, Copetti R: Pediatric chest ultrasound versus conventional radiology: experimental evidence first. Pediatr Radiol 2014, 44(7):900.

4. Vergine M, Copetti R, Brusa G, Cattarossi L: Lung Ultrasound Accuracy in Respiratory Distress Syndrome and Transient Tachypnea of the Newborn. Neonatology 2014, 106(2):87-93.

5. Raimondi F, Migliaro F, Sodano A, Umbaldo A, Romano A, Vallone G, Capasso L: Can neonatal lung ultrasound monitor fluid clearance and predict the need of respiratory support? Crit Care 2012, 16(6):R220.

6. Raimondi F, Migliaro F, Sodano A, Ferrara T, Lama S, Vallone G, Capasso L: Can neonatal chest ultrasound predict the failure of non-invasive ventilation? Pediatrics 2014.

doi:10.1186/1824-7288-40-S2-A25

Cite this article as: Raimondi et al:: Point-of care lung ultrasound in the NICU: uses and limitations of a new tool. Italian Journal of Pediatrics 2014 40(Suppl 2):A25.

\section{Submit your next manuscript to BioMed Central and take full advantage of:}

- Convenient online submission

- Thorough peer review

- No space constraints or color figure charges

- Immediate publication on acceptance

- Inclusion in PubMed, CAS, Scopus and Google Scholar

- Research which is freely available for redistribution

Submit your manuscript at www.biomedcentral.com/submit
C BioMed Central 